\title{
OBSERVANDO AULAS DE BIOLOGIA EM UMA ESCOLA NO EXTREMO SUL CATARINENSE
}

\author{
Juliana Borghezan ${ }^{1}$ \\ Miriam Da Conceição Martins ${ }^{2}$
}

\section{RESUMO}

A presente pesquisa teve por objetivo compreender o processo de ensino-aprendizagem na disciplina de Biologia. Ocorreu no primeiro semestre de 2017, com uma turma de segundo ano do ensino médio, observaram-se seis aulas, no período matutino. A Escola de Educação Básica Toneza Cascaes pertence ao município de Orleans/SC. Foram envolvidos no estudo vinte oito (28) alunos. A metodologia utilizada foi qualitativa, como instrumento de pesquisa aplicamos um questionário, contendo questões objetivas e subjetivas. A partir dos resultados, constatamos que os estudantes possuem algumas dificuldades na disciplina, pelos conteúdos e forma de ensino. E que escola precisa de laboratório e biblioteca equipados. Entretanto, considerou-se uma experiência enriquecedora, pois a observação estabeleceu um primeiro contato com os alunos, professores e escola, oportunizando a adaptação a esse novo ambiente até então desconhecido na prática.

Palavras-chave: Observação; Ensino Médio; Biologia.

\section{WATCHING BIOLOGY CLASSES IN A SCHOOL IN THE SOUTH CATARINIAN}

\section{ABSTRACT}

The present research seek to understand the teaching-learning process in the biology discipline. It happened in the first half of 2017, with a first sixth year of high school, there were six classes in the morning. The Elementary Toneza Cascaes belongs to the municipality of Orleans / SC. Twenty eight (28) students were enrolled in the study. The methodology used was qualitative, as a research instrument we applied a questionnaire, containing objective and subjective questions. From the results, we find that the students have some difficulties in the discipline, by the content and the way of teaching. And what school needs a laboratory and a library equipped. However, it was considered an enriching experience, since the observation established a first contact with the Students, teachers and school, allowing the adaptation to this new environment hitherto unknown in practice.

Keywords: Observation; High School; Biology.

\footnotetext{
${ }^{1}$ Mestranda do Programa de Pós-Graduação em Ciências Ambientais (PPGCA), pesquisando na área de Etnobotânica Urbana, com ênfase em Plantas Medicinais; borghezanj@outlook.com

${ }^{2}$ Possui graduação em Ciências Habilitação Biologia pela Universidade do Extremo Sul Catarinense - Criciúma; Especialização em Ciências opção Biologia pela FURB -Blumenau; Mestrado em MASTER EN EDUCACIÓN pelo Instituto Pedagógico Latinoamericano y Caribeño em convênio com UNESC; Mestrado em Educação pela UNESC- Criciúma. Doutorado em Ciências da Saúde pelo Programa de Pós-Graduação em Ciências da Saúde-PPGCS, da UNESC - Criciúma. mcm@unesc.net
} 


\section{INTRODUÇÃO}

Sabemos que o educador possui papel fundamental na formação dos educandos, com isso, muitas experiências são vivenciadas diariamente no âmbito escolar, mas nem sempre se tem a oportunidade de presenciá-las. Entretanto, observa-se que, a educação brasileira não é considerada uma das melhores, embora, apresente-se em constante transformação. Segundo Gadotti (2000, p. 6), encontra-se em uma "dupla encruzilhada", onde:

\footnotetext{
De um lado, o desempenho do sistema escolar não tem dado conta da universalização da educação básica de qualidade; de outro, as novas matrizes teóricas não apresentam ainda a consistência global necessária para indicar caminhos realmente seguros numa época de profundas e rápidas transformações (GADOTTI, 2000, p. 6).
}

É necessário, portanto, que os atores deste cenário, que hoje se encontra bastante desafiador, busquem acompanhar o que vem acontecendo, para, de alguma forma trazer melhorias à educação. Pois, segundo Luckesi (2008, p. 122), alguns docentes cumprem o seu papel mecanicamente, sem investir o necessário para que os resultados de sua atividade sejam significativos. Desta forma, pouco se tem a contribuir para a qualidade do ensino e efetiva aprendizagem do educando. $O$ simples pensar a mudança, de acordo com Martelli (2004), não a faz ocorrer, é preciso transformar o modo de pensar e agir, embora isso seja um processo lento, onde, na maioria das vezes, o resultado só aparece após um longo período de espera, no entanto, não deve ser visto como um obstáculo e sim, como um impulso ao início da mudança.

A docência, portanto, envolve saberes, conhecimentos científicos, pedagógicos e educacionais, onde procura-se mediar situações que perpassam na vida dos alunos, questionando maneiras de produzir e distribuir conhecimentos a partir de uma sensibilização (MARANDINO; SELLES; FERREIRA, 2009). Ou seja, o ato de ensinar requer, não apenas, voltar-se à sala de aula, e sim à realidade do educando, que vai além dos muros da escola e que reflete diretamente na aprendizagem do 
mesmo. Para isso, algumas virtudes são necessárias ao educador, de acordo com Freire (1982):

1. Ser coerente entre o que se diz e o que se faz;

2. Saber trabalhar a tensão entre a palavra e o silêncio;

3. Trabalhar criticamente a tensão entre a subjetividade e a objetividade;

4. Diferenciar o aqui e agora do educador do aqui e agora do educando;

5. Evitar o espontaneismo sem cair na manipulação;

6. Vincular teoria e prática;

7. Praticar uma paciência impaciente;

8. Ler o texto a partir da leitura do contexto.

A última virtude, que diz "ler o texto a partir da leitura do contexto", referese ao que se está querendo dizer, o fato de aproximar o conteúdo que se quer ensinar, da realidade do educando, visto que, a partir dessa significação dada, o mesmo passa a se sentir sujeito do processo de ensino-aprendizagem.

Para Freire (2001, p. 21), "uma das bonitezas da prática educativa está exatamente no reconhecimento e na assunção de sua politicidade que nos leva a viver o respeito real aos educandos ao não tratar, de forma sub-reptícia ou de forma grosseira, de impor-Ihes nossos pontos de vista." Ou seja, o educador, na condição de mediador do conhecimento, não deve considerar somente aquilo que a ciência conhece, mas sim o que o educando traz consigo, de forma empírica, para então se basear e concretizar àquela informação.

Com isso, a escola apresenta-se como um ambiente bastante curioso, fazendo-nos querer saber mais sobre o que se passa e como acontece a troca de saberes dentro e fora da sala de aula. Tendo em vista que, de acordo com Luckesi (2008, p. 126), o objetivo principal da escola é "o desenvolvimento das capacidades cognoscitivas, uma vez que para o desenvolvimento das convicções sociais e para o desenvolvimento das habilidades motoras e do modo de viver muitas outras instâncias sociais, além da escola, contribuem".

A Escola de Educação Básica (EEB) Toneza Cascaes, escolhida para realização da presente pesquisa, pertence à rede Estadual de ensino, e encontra-se localizada no município de Orleans, Santa Catarina. Possui como objetivo geral: 
Oferecer condições para que todos os alunos desenvolvam suas capacidades e aprendam os conteúdos necessários para construir instrumentos de compreensão da realidade e de participação em relações sociais, políticas e culturais diversificadas cada vez mais amplas, condições estas fundamentais para o exercício da cidadania na construção de uma sociedade democrática e não excludente (EEB, 2016, p. 7).

O processo de ensino-aprendizagem da mesma fundamenta-se no sociointeracionismo, como prevê a Proposta Curricular de Santa Catarina. Diante de tal concepção de aprendizagem, o ser humano é entendido como social e histórico, portanto, o foco da aprendizagem está na interação que ocorre entre contextos históricos, sociais e culturais, enquanto que a formação de conceitos científicos dá-se a partir de conceitos cotidianos (EEB, 2016). Esta proposta, prevê como eixos fundamentais: as concepções de homem e aprendizagem, sendo a primeira relacionada ao homem que se quer formar, construindo um modelo de sociedade, já a segunda refere-se à "o que ensinar", para compreensão e provocação da relação entre o ser humano e o conhecimento (SANTA CATARINA, 1998). De fato, Correia (2007, p. 7) conclui que, "a construção do currículo se abriga na cultura e esta, pela sua pluralidade, contempla a história do aprendizado humano, ao longo do tempo, perpassando as tensões, conflitos e inconvenientes que os fatores políticos, econômicos e sociais impõem ao contexto educacional".

Observa-se, a partir deste contexto a preocupação em aproximar o conteúdo transmitido ao estudante, com base na realidade a qual este encontra-se inserido. Ocorrendo parte dessa responsabilidade ao docente que, segundo Santos et al. $(2014$, p. 13),

É a ponte de mediação entre o aluno em formação e o meio social no qual está inserido; uma vez que ele vai através de instruções, conteúdos e métodos orientar aos seus alunos a viver socialmente. Sendo a educação um fenômeno social necessário à existência e funcionamento de toda a sociedade, exige-se a todo instante do professor as competências técnicas e teóricas para a transmissão desses conhecimentos que são essenciais para a manutenção e progresso social (SANTOS, et al., 2014, p. 13).

Como forma de aproximar-se desta realidade escolar, a presente pesquisa teve por objetivo compreender o processo de ensino-aprendizagem na disciplina de Biologia. 
Trata-se de uma pesquisa qualitativa que, Segundo Lüdke e André (1986), realiza-se em seu ambiente natural como fonte direta dos dados, sendo o pesquisador o principal instrumento. De cunho exploratório, descritivo e de campo.

Para isso, foi selecionada uma turma de segundo ano do ensino médio, na disciplina de Biologia, possuindo 28 estudantes, entre 15 e 19 anos de idade. A coleta de dados ocorreu por meio da aplicação de um questionário, contendo questões objetivas e subjetivas. Assim, aplicou-se o instrumento de pesquisa com os estudantes, a professora e a diretora, que consistiu em um questionário, com o objetivo de coletar dados sobre o processo de ensino-aprendizagem de Biologia. O autor Gil (2008, p. 121) define questionário como sendo uma "técnica de investigação composta por um conjunto de questões que são submetidas a pessoas com o propósito de obter informações sobre conhecimentos, crenças, sentimentos, valores, interesses, expectativas, aspirações, temores, comportamento presente ou passado". Portanto, mostra-se como uma técnica bastante viável e pertinente para ser empregada quando, segundo Chaer; Diniz e Ribeiro (2011, p. 1), "se trata de problemas cujos objetos de pesquisa correspondem a questões de cunho empírico, envolvendo opinião, percepção, posicionamento e preferências dos pesquisadores.

Sendo assim, observaram-se seis aulas no período matutino, de 07/03 a 23/03/2017. O período destinado à observação, de acordo com Lüdke e André (1986, p. 26), "permite que o observador chegue mais perto da "perspectiva dos sujeitos", um importante alvo nas abordagens qualitativas". Esta é uma possibilidade de observar como vêm sendo desenvolvido o ensino de um modo geral, em especial a disciplina de Biologia que interessa à pesquisadora em questão.

\section{Local do estudo}

A Escola de Educação Básica (EEB) Toneza Cascaes, está situada na Rua Luiz Pizzolatti Sobrinho, ㄲo 222 - Bairro Santista, município de Orleans/SC. A mesma é mantida pelo Governo do Estado de Santa Catarina e administrada pela Secretaria de Estado da Educação, funcionando regularmente pelos seguintes atos: Decreto de Criação ํo 3401 de 21 de setembro de 1977 e Lei no 3552 de 19 de novembro de 1964 
(EEB, 2016). Oferece Educação Básica compreendendo o Ensino Fundamental II e Ensino Médio nos períodos matutino, vespertino e noturno, sendo este último destinado ao ensino médio. Recebe estudantes dos mais diversos locais, desde comunidades do interior até do centro da cidade.

A organização escolar é composta por diretores, assessores, técnico pedagógico, técnico administrativo, secretárias, que inclui assistente de educação, corpo discente e corpo docente, além de merendeiras e auxiliares de serviços gerais. Quanto à sua estrutura física, possui salas climatizadas e espaços bastante amplos, distribuídos em: biblioteca, ginásio de esportes, cozinha, sala dos professores, secretaria, direção, sala de informática e de vídeo, laboratório, espaço para o lanche, bem como, outras atividades. A locomoção dos estudantes até a escola envolve desde transportes escolares (ônibus), carros, e ainda àqueles que, por residirem próximo à escola o fazem a pé.

\section{RESULTADOS E DISCUSSÃO}

Análise do questionário aplicado com os estudantes:

Quase todos (92\%) afirmaram que a escola possui um laboratório, mas este não é utilizado pela professora porque não possui os equipamentos necessários. Para Berezuk e Inada (2010), as aulas práticas são essenciais para que os alunos assimilem os conteúdos abordados por meio de teorias, facilitando a aprendizagem. Em relação aos conteúdos, muitos (81\%) entendem o que a professora explica, mas apresentam dificuldade em temas como citologia (60\%), por exemplo, (figura 1) em relação às organelas citoplasmáticas. Em outro momento, 34\% relataram possuir dificuldade em "decorar" os nomes científicos. Miranda (2007) acredita que o que propicia a aprendizagem é um ambiente onde seja permitido que os alunos elaborem propostas, explorações e investigações sobre problemas oriundos que acontecem no seu dia-a-dia. Isso porque, muitos acabam não expressando suas dúvidas devido à falta de abertura ao diálogo, o que deveria ser uma constante, a possibilidade de o educando expressar-se diante das dificuldades, que resultaria em melhor desempenho. 


\section{CRIAR EDUCAÇÃOO}

Revista do Programa de Pós-Graduação em Educação - UNESC

Criar Educação, Criciúma, v. 8, no2, ago/dez 2019.- PPGE - UNESC ISSN 2317-2452

Embora o conteúdo que, quase metade (45\%) dos estudantes deseja que seja mais enfatizado tenha sido o de anatomia humana, principalmente os temas reprodução e sexualidade. Rodrigues e Scheid (2008) afirmam que, muitos professores, ao abordarem sobre o corpo humano, falam de reprodução sem considerar a sexualidade como parte integrada, sendo que uma das funções da escola é sanar estas dúvidas que os estudantes possuem, principalmente enquanto adolescentes, a fim de orientá-los quanto à questão da saúde sexual. Outros conteúdos citados foram origem da vida, zoologia, citologia, taxonomia e vírus.

Figura 1 - Conteúdos que os estudantes possuem mais dificuldade nas aulas de Biologia.

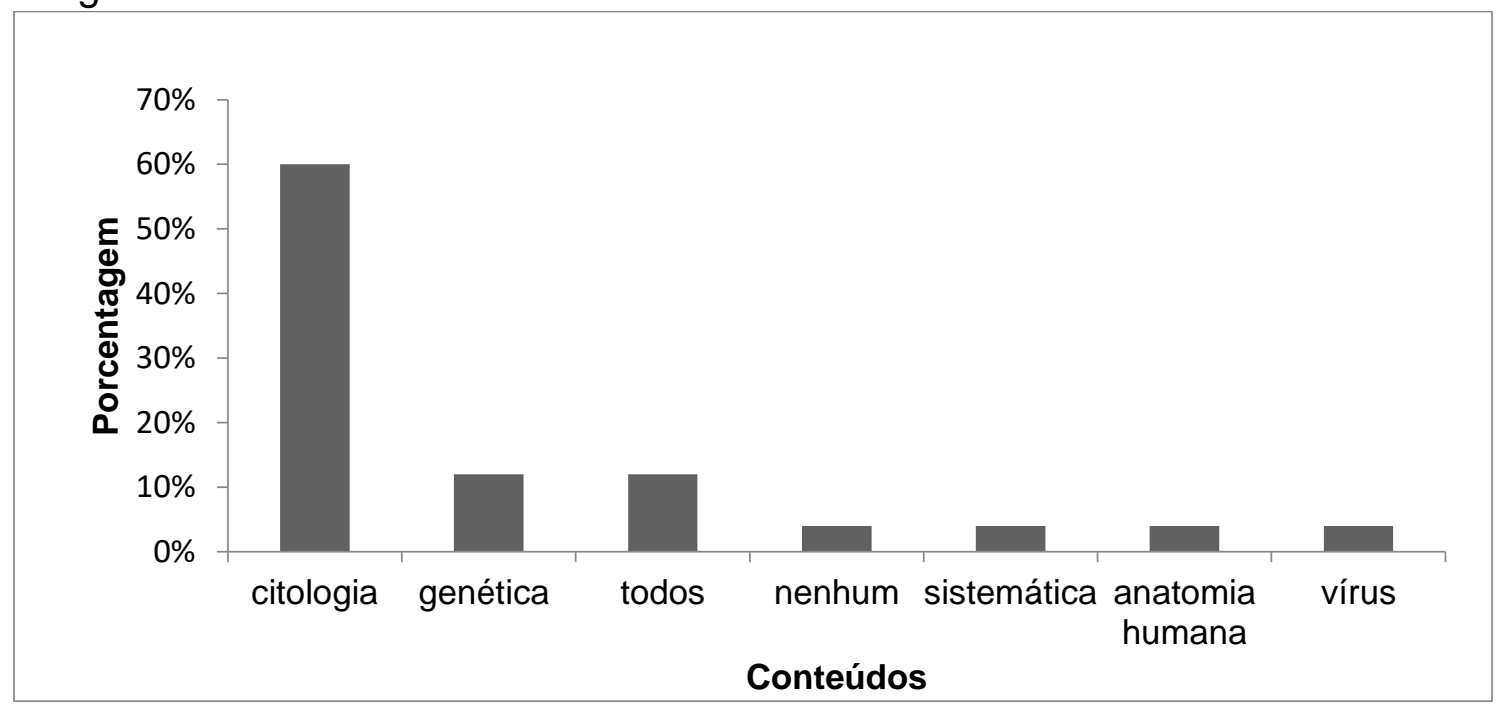

Fonte: Das autoras, (2017).

De acordo com $77 \%$ dos estudantes, a professora utiliza maneiras diferentes para ministrar as aulas, embora, em outro momento, $69 \%$ tenham afirmado não aprender sobre temas atuais em sala de aula. Ou seja, observou-se uma contradição nas respostas. Quando questionados sobre como gostariam que acontecessem as aulas de Biologia, os mesmos destacaram a dinâmica (61\%) como um método eficaz de ensino. Autores como Silva e Dornfeld (2016), ao analisar a opinião dos alunos sobre a utilização de dinâmicas, também acreditam que a aplicação de dinâmicas auxilia tanto no ensino, como nas relações interpessoais do professor com seus alunos. De fato, a aula torna-se muito mais agradável quando todos participam ativamente. Ao questionar-se sobre o interesse em saber como seria 


\section{CRIAR EDUCAÇÃO}

Revista do Programa de Pós-Graduação em Educação - UNESC

Criar Educação, Criciúma, v. 8, no2, ago/dez 2019.- PPGE - UNESC ISSN 2317-2452

uma aula no laboratório, $31 \%$ responderam que fazendo experimentos no laboratório seria uma maneira diferenciada de aprender (figura 2). Berezuk e Inada (2010) consideram a experimentação algo desejável pelos alunos, permitindo visualizar o que está sendo, muitas vezes, representado no livro didático.

Figura 2 - Metodologias que deveriam ser utilizadas nas aulas de Biologia, segundo os estudantes.

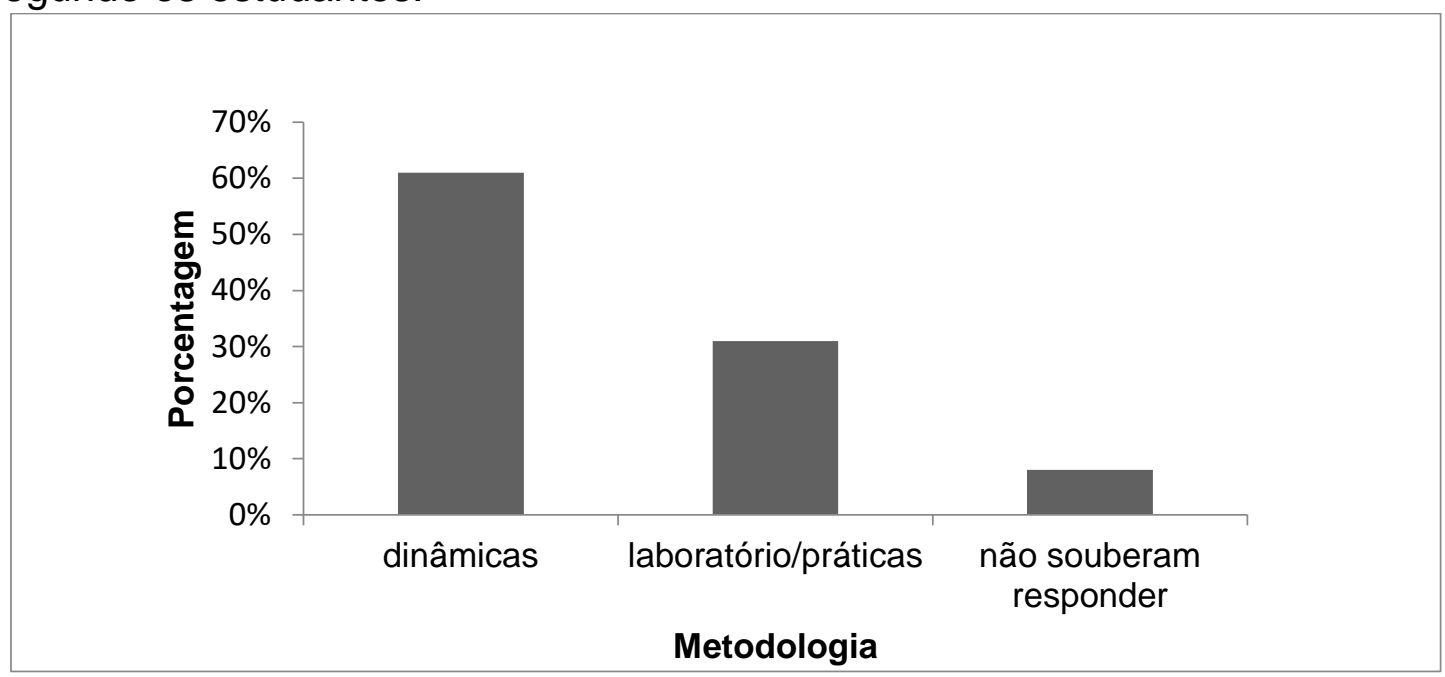

Fonte: Das autoras, (2017).

Todos $(100 \%)$ consideraram a tecnologia como um meio que pode ser explorado na sala de aula. Faria (2011) utilizando a plataforma Moodle como metodologia de ensino, conclui que é possível motivar e incentivar os alunos a aprenderem por meio de atividades planejadas com o apoio de recursos tecnológicos. A música também demonstrou ser útil para o aprendizado, visto que $35 \%$ dos educandos afirmaram gostar e tocar algum tipo de instrumento, dentre eles bateria, violão, violino, piano, flauta, teclado, guitarra, saxofone e clarinete. A utilização de paródia, por exemplo, como método alternativo de ensino é viável, pois torna a aula interativa e interessante na visão do aluno, levando-o a se empenhar em compreender o conteúdo para elaboração da letra, despertando a criatividade (SILVA; PEREIRA; MELO, 2015). Assim, segundo Carvalho (2008), os estudantes consideram a música 
uma alternativa de aprendizagem, sendo um importante recurso didático, que leva-os a compreender determinados conteúdos. Quanto à avaliação escolar, 39\% das respostas, deveria ser baseada no comportamento e participação nas aulas, outros $34 \%$ acreditam que provas e trabalhos sejam a melhor forma. A avaliação escolar, segundo Santos et al. (2014, p. 11)."é uma tarefa complexa que não se resume à realização de provas e atribuição de notas, ela cumpre funções pedagógico-didáticas, de diagnóstico e de controle em relação ao rendimento escolar".

Análise do questionário aplicado com a professora:

A mesma relatou que na escola o projeto político-pedagógico (PPP) envolve discussões e é elaborado a cada início de ano. As horas atividades são utilizadas para a preparação de aulas, materiais didáticos, planejamento e correção das avaliações. Quanto ao que poderia ser melhorado na escola, para que as aulas de Biologia fossem mais bem aproveitadas, comentou-se que o laboratório "está sendo trazido para uma sala mais ampla, sugerindo-se a compra de equipamentos faltantes, como por exemplo, a lâmpada do microscópio, para contribuir com os estudos." Lima e Garcia (2011) investigando a importância das aulas práticas de Biologia no ensino médio, concluíram que embora não haja recursos suficientes em algumas escolas, o ensino não deve se restringir apenas ao laboratório, pois este pode acontecer em qualquer ambiente, capaz de estimular a aprendizagem, de modo que os alunos participem ativamente, refletindo e opinando sobre 0 assunto. Possobom; Okada e Diniz (2003) concordam dizendo que, com relação aos laboratórios, é possível contornar a situação, unindo esforços, adaptando ambientes e utilizando materiais acessíveis, fugindo do tradicionalismo e proporcionando aulas mais diferenciadas aos alunos. É preciso, segundo Santos et al. (2014), que os conteúdos aplicados pelo professor tenham como fundamento, não só a transmissão das informações de uma disciplina, mas apresentem relação com a realidade dos discentes e que sirvam para que os mesmos possam refletir sobre os desafios impostos pela vida cotidiana.

Esporadicamente, na escola acontece uma feira científico-cultural, onde são enfatizados diferentes assuntos, a mesma colabora nas viagens de estudos (curta 
distância) e participação em eventos, que comumente são organizadas pelos professores, assistentes técnico-pedagógicas e direção. O plano de ensino da disciplina é elaborado com base na Proposta Curricular de Santa Catarina e nos Parâmetros Curriculares Nacionais. Quanto à biblioteca, a professora afirma que existe, mas acredita não possuir obras suficientes relacionadas à sua disciplina. Perucchi (1999) considera que, para um ensino de qualidade, no mínimo deve-se possuir uma biblioteca em funcionamento e bem estruturada, que sirva de suporte para o processo de ensino-aprendizagem. Ou seja, a biblioteca é uma ferramenta indispensável para educação, devendo dispor de acervos valiosos para consulta daqueles que dela usufruírem.

$\mathrm{Na}$ opinião da professora, a maior dificuldade em lecionar é despertar o interesse dos alunos pelos estudos. Braga et al. (2012), consideram necessária a busca de inovações por parte dos docentes, resultando no aperfeiçoamento dos conteúdos e utilização de novas metodologias, dada a importância da interdisciplinaridade e a acessibilidade às informações nos dias de hoje. Ou seja, o professor que continuar somente repassando informação, sem preocupar-se com as atualizações do meio, comprometerá o desempenho de seus alunos. Para avaliar os educandos, segundo a professora, utilizam-se diversas ferramentas como a realização de provas, elaboração de trabalhos, questões orais, além de formas lúdicas de aprendizagem. Segundo Davis (1991), a escola precisa de um professor que avalie com precisão o processo de construção do conhecimento, encarando o erro como uma forma de aprendizado para o aluno. Isso porque, segundo a professora, a maioria participa ativamente das aulas e se esforça para entender o conteúdo. Ou seja, não se pode apenas levar em conta a nota que o estudante recebeu em determinada prova/trabalho, é preciso enxergar além do que está escrito, sendo que, muitas vezes, a dificuldade pode estar na própria escrita e não na aprendizagem do mesmo.

Para finalizar, análise do questionário à diretora da escola:

Segundo a diretora, a escola dispõe de um laboratório de Biologia e, este se encontra em condições de uso. Quanto à elaboração de materiais didáticos, a mesma afirma que os alunos não participam da construção de nenhum tipo de material, evidenciando tal necessidade. Alves et al. (2016) discutindo sobre os recursos didático-pedagógicos, consideram que caso não haja recursos disponíveis 
na escola, cabe ao professor e comunidade escolar buscarem alternativas que possibilitem a diversidade das aulas, a fim de despertar no aluno o interesse pelo aprendizado. Equipamentos como data show, retroprojetor, fotocopiadora, DVD, televisor, computador, tela de projeção (telão) e máquina fotográfica estão disponíveis na escola e para utilizá-los basta agendar. A diretora afirma que a escola possui biblioteca atualizada, e oferece palestras e outras atividades aos seus alunos, quando pertinente.

\section{CONSIDERAÇÕES FINAIS}

Por meio desta pesquisa, foi possível verificar o comportamento e o comprometimento dos educandos em aprender os conteúdos, percebendo o interesse em realizar as atividades propostas pela educadora. Observou-se também a relação desta com os estudantes, assim como a metodologia adotada para transmissão dos conteúdos. Segundo Reis (2011), a observação constitui um elemento-chave no processo avaliativo sobre o desempenho do docente, sendo um desafio para o seu desenvolvimento e servindo de apoio para identificar e superar fragilidades individuais e coletivas. Portanto, este contato, aproximou a pesquisadora da possível realidade com a qual se deparará futuramente em sua carreira profissional.

Além disso, essa experiência consistiu em uma ferramenta para trabalhar algumas questões, recorrentes nas escolas, como a falta de um laboratório bem equipado, a carência de dinâmicas, bem como de incentivo dos educadores em tornar as aulas mais didáticas. Assim como, a necessidade de aproximar os conteúdos da realidade dos educandos, possibilitando uma melhor compreensão.

Pode-se observar que, o "tradicionalismo" ainda encontra-se enraizado na escola, em detrimento de algumas atitudes relatadas pelos estudantes. Sendo que, em vista das transformações que ocorrem, segundo Gadotti (2000, p. 8), "a escola precisa ter projeto, precisa de dados, precisa fazer sua própria inovação, planejar-se a médio e longo prazo, fazer sua própria reestruturação curricular, elaborar seus parâmetros curriculares, enfim, ser cidadã". Ou seja, é necessário se "atualizar", desapegando-se de antigos padrões, passando a integrar a tecnologia e tudo o que 
há de mais novo na atualidade, como forma de contribuir para o ensino-aprendizagem.

A Escola Cidadã a que Gadotti se refere, segundo Padilha (2002, p. 88) é:

\begin{abstract}
Uma escola amiga, companheira, bonita, alegre e prazerosa que, está sendo construída e permanentemente reconstruída com base na ousadia, na criatividade, na vontade, no desejo e na ação política de pessoas comprometidas com a educação do presente e do futuro, sujeitos concretos e históricos que desafiam o imobilismo, que não se conformam diante do descaso com a coisa pública, que buscam sem cessar repensar as suas próprias práticas e que são conscientes e críticos na sua cotidianeidade (PADILHA, 2002, p. 88).
\end{abstract}

Portanto, a experiência vivida tornou-se bastante enriquecedora, pelo fato de proporcionar uma aproximação, tanto da escola, quanto da professora e dos estudantes. Sendo que, para nós, licenciandos, este contato com a realidade é fundamental para o nosso desenvolvimento pessoal e profissional.

\title{
REFERÊNCIAS
}

ALVES, E. M; NASCIMENTO, L. M. C. T; FRENEDOZO, R. C; SCHIMIGUEL, J. Recursos didático-pedagógicos no ensino de Ciências e Biologia. Ciclo Revista: IF Goiano, 2016.

BEREZUK, P. A; INADA, P. Avaliação dos laboratórios de ciências e biologia das escolas públicas e particulares de Maringá, Estado do Paraná. Acta Scientiarum: human and social sciences. Maringá, v. 32, n. 2, 2010.

BRAGA, C. C. G; ROSA, E. D; SILVA, I. C; OLIVEIRA, J. A. Relação entre as práticas pedagógicas utilizadas por docentes de ciências e biologia das escolas estaduais de Oliveira, MG e a indisciplina. 2012.

CARVALHO, V. F. O processo de construção de paródias musicais no ensino de Biologia na EJA. Dissertação (Mestrado em Ensino de Ciências e Matemática). Pontifícia, Universidade Católica de Minas Gerais, 2008.

CHAER, G; DINIZ, R. R. P; RIBEIRO, E. A. A técnica do questionário na pesquisa educacional. Evidência, Araxá, v. 7, n. 7, p. 251-266, 2011.

CORREIA, M. L. A construção do currículo escolar: respeito à identidade e à subjetividade das teorias na formação educacional do aluno. UTPPR. EDUCERE XIII Congresso Nacional de Educação, 2007.

DAVIS, C. O papel e a função do erro na avaliação escolar. Revista Brasileira de Estudos Pedagógicos, 1991. 
EEB. Escola de Educação Básica Toneza Cascaes. Projeto político-pedagógico. Orleans, 2016.

FARIA, K. C. Utilizando resultados de atividades com tecnologias digitais como elementos constituintes da avaliação: uma experiência na disciplina de biologia no ensino médio. Dissertação (Mestrado em Ensino de Ciências e Matemática). Pontifícia, Universidade Católica do Rio Grande do Sul, 2011.

FREIRE, P. Virtudes do educador. Editora Vereda, 1982. 14 p.

Política e educação: ensaios. 5 ed. São Paulo: Cortez, v. 23, 2001. 57 p.

GADOTTI, M. Perspectivas atuais da educação. São Paulo em Perspectiva, v. 14, n. 2, 2000.

GIL, A. C. Métodos e técnicas de pesquisa especial. 6 ed. São Paulo: Atlas, 2008. $220 \mathrm{p}$.

LIMA, D. B; GARCIA, R. N. Uma investigação sobre a importância das aulas práticas de Biologia no Ensino Médio. Cadernos do Aplicação, Porto Alegre, v. 24, n. 1, 2011.

LUCKESI, C. C. Avaliação da aprendizagem escolar: estudos e proposições. 19. ed. São Paulo: Cortez, 2008.

LÜDKE, M; ANDRÉ, M. E. D. A pesquisa em educação: abordagens qualitativas. São Paulo: EPU, 1986. 112 p.

MARANDINO, M; SELLES, S. E; FERREIRA, M. S. Ensino de biologia: histórias e práticas em diferentes espaços educativos. São Paulo: Cortez, 2009.

MARTELLI, J. M. Os Desafios da Prática Pedagógica do Ensino de Ciências Biológicas frente às Mudanças de Paradigmas. Dissertação (Mestrado em Educação). PUCPR - Curitiba, 2004.

MIRANDA, E. S. Reflexões e desafios na construção de um projeto interdisciplinar no ensino médio. Dissertação (Mestrado em Educação em Ciências e Matemática). Porto Alegre: PUC, 2007.

PADILHA, P. R. Uma escola mais bela, alegre e prazerosa. Lecciones de Paulo Freire, Cruzando Fronteiras. 2002.

PERUCCHI, V. A importância das bibliotecas nas escolas públicas municipais de Criciúma - Santa Catarina. Revista ACB: Biblioteconomia em Santa Catarina, Florianópolis, v. 4, n. 4, 1999. 


\section{CRIAR EDUCAÇÃO}

Revista do Programa de Pós-Graduação em Educação - UNESC

Criar Educação, Criciúma, v. 8, n2, ago/dez 2019.- PPGE - UNESC ISSN 2317-2452

POSSOBOM, C. C. F; OKADA, F. K; DINIZ, R. E. S. Atividades práticas de laboratório no ensino de biologia e ciências: relato de uma experiência. Núcleos de ensino. São Paulo: Unesp, 2003. p. 113-123.

REIS, P. Observação de aulas e avaliação do desempenho docente. Ministério da Educação: conselho científico para avaliação de professores (CCAP), 2011.

RODRIGUES, L. R; SCHEID, N. M. J. Os conhecimentos básicos que os adolescentes possuem sobre sexualidade e o papel do professor de Biologia neste contexto. Revista Educação. Santa Maria, v. 33, n. 3, 2008.

SANTA CATARINA. Proposta curricular de Santa Catarina. Educação Infantil, Ensino Fundamental e Médio: Disciplinas Curriculares. Florianópolis: COGEN, 1998.

SANTOS, E. P; et al. O processo didático educativo: uma análise reflexiva sobre o processo de ensino e aprendizagem. 2014. Disponível em:

$<$ http://www.webartigos.com/artigos/o-processo-didatico-educativo-uma-analisereflexiva-sobre-o-processo-de-ensino-aprendizagem/117343/>. Acesso em: 12/07/2017.

SILVA, D. T; DORNFELD, C. B. Dinâmicas de grupos em aulas de biologia: uma proposta motivacional para aprendizagem. Revista Eletrónica de Enseñanza de Iãs Ciencias, v. 15, n. 1, 2016.

SILVA, E. S. P; PEREIRA, I. B; MELO, S. M. F. O uso da música no ensino de Biologia: experiências com paródias. I Congresso de Inovação Pedagógica em Arapiraca. Perspectivas atuais dos profissionais da educação: desafios e possibilidades. 2015.

Recebido 30 de novembro 2018

Aprovado 25 de maio de 2019. 